\title{
MULTI RESOURCE CONSTRAINED PROJECT SCHEDULING ON CRITIC
}

\section{METHOD}

\author{
A. BHARGAV ${ }^{1}$, N. VENKATACHALAPATHI ${ }^{2}$ \& M. L. S. DEVA KUMAR ${ }^{3}$ \\ ${ }^{l}$ Research Scholar, Department of Mechanical Engineering, JNTUA College of Engineering, Ananthapuramu,
} Andhra Pradesh, India

${ }^{2}$ Department of Mechanical Engineering, Annamacharya Institute of Technology and Sciences, Rajampet,

Andhra Pradesh, India

${ }^{3}$ Department of Mechanical Engineering, JNTUA college of Engineering, Ananthapuramu,

Andhra Pradesh, India

\begin{abstract}
In this paper we consider the critic method resource-constrained project scheduling problem (CMRCPSP). In this paper, a text problem is considered in a critic method is developed. The objective function is the minimization of the project completion time and critical path. A weighted sum of resources for each activity is obtained and the activities are ranked based on weighted sum and scheduled.The method is explained all the way through numerical illustration All steps of the proposed solution methodology are plotted in detail Gantt chart shows that our results.
\end{abstract}

KEYWORDS: Project Scheduling (PS), Critic Method \& Resource Allocation

Received: Jun 09, 2020; Accepted: Jun 29, 2020; Published: Jul 25, 2020; Paper Id.: IJMPERDJUN2020461

\section{INTRODUCTION}

The resource-constrained project scheduling problem (RCPSP) The basic form of resource-constrained project scheduling problem is as mentioned. However, since the situation is completely different in practice, changes have been made to the basic assumptions by the researchers over time. In addition have shown that the RCPSP problem belongs to the class of the strongly NP-hard problems. As a result, various solutions are used according to the changes in the basic assumptions. In the following, changes which have occurred in the general form of the base problem over time are evaluated and categorized from the perspective of four main dimensions and their subcategories, accordingAs mentioned earlier; each activity in the project requires resources to be implemented. The need to resources, only in the form of renewable resources and assuming that they have a full capacity in each period and a fixed amount of the resource is occupied during the implementation of the activity, has been assessed in the basic RCPSP. Since the type of the consumption resource(s) of an activity depends on the nature of that activity, various resources have been evaluated, among which renewable, nonrenewable and doubly constrained resources have attracted the most attention from the researchers.

\section{LITERATURE REVIEW}

Since One CRITIC (Criteria Importance Through Intercriteria Correlation) method is one of the weighting methods which determines objective weights for criteria. CRITIC method was proposed by Diakoulaki et al. in 1995. This method includes the intensity of the contrast and the conflict in the structure of the decision making problem (Diakoulaki et al., 1995). It uses correlation analysis to find out the contrasts between criteria (Y1lmaz 
and Harmancioğlu, 2010). In this method the decision matrix is evaluated and the standard deviation of normalized criterion values by columns and the correlation coefficients of all pairs of columns are used to determine the criteria contrast (Madić and Radovanović, 2015). In the literature there are many applications of CRITIC method. Diakoulaki et al. (1995) applied CRITIC method to a sample of Greek pharmaceutical industries evaluated with regard to three of the most prominent indices of a firm's performance. Yılmaz and Harmancioğlu (2010) developed a water resource management model for the Gediz River Basin in Turkey. The management alternatives were evaluated with Simple Additive Weighting (SAW), Compromise Programming (CP) and Technique for Order Preference by Similarity to Ideal Solution (TOPSIS). During these evaluations entropy method, CRITIC method and the standard deviation method were used for objective criteria and Analytic Hierarchy Process (AHP) method was used for subjective criteria. Aznar Bellver et al. (2011) determined the value of a Spanish savings. During this valuation CRITIC method was used for finding the weight of variables and companies. Milić and Goran (2012) presented the algorithms of entropy, CRITIC and FANMA methods in detail. Then application of these methods was shown with an illustrative example and results namely the values of criteria weights were compared. Guo et al. (2013) aimed to construct an evaluation index system of city's soft power. For this aim they used AHP and CRITIC methods to determine index weight. Çakır and Perçin (2013) conducted the performance measurement of 10 logistics firms with three stage MCDM techniques. The weights of the criteria were determined with the CRITIC method at the first stage. Liu and Zhao (2013) proposed a dynamic comprehensive evaluation method with subjective and objective information. For this aim they used the combination of AHP and CRITIC methods to determine the index weight. Kazan and Ozdemir (2014) analyzed financial statements of the fourteen large-scale conglomerates which were traded on Istanbul Stock Exchange. Firstly nineteen financial ratios of these holdings and their financial ratio weights were calculated by CRITIC method and then financial performance scores were found by TOPSIS method. Alemiardakani (2014) used the entropy method, the Modified Digital Logic (MDL) method, CRITIC method, Numeric Logic, (NL) and Adjustable Mean Bars' (AMB). Then a combinative weighting scheme was proposed and used in the TOPSIS model. Iris (2014) generated a systematic approach to develop sustainability index for urban water management system in Macau. In this study a comparative analysis was conducted between CRITIC and AHP methods with the equal weighting method in evaluating urban water sustainability index. Kim and Yu (2015) proposed a real feature matching method. In this method the shape similarity between the candidate pairs in the two data sets through a linear sum of the weight was calculated computed using the CRITIC method. Madic and Radovanović (2015) handled the selection of the most appropriate Non-Traditional Machining Process (NTMP) for a given machining application. In this application the relative significance of criteria was determined with CRITIC method and considered complete ranking of competitive NTMPs are found with ROV method. Lu et al. (2015) used the combination of AHP and CRITIC methods to calculate the index evaluation system of educational information and determine the impact of the assessment indicators for education information development in Suzhou region.

\section{PROBLEM DESCRIRITION}

Here the Table 1 shows the example taken from the illustration gives the Here it gives the information about the activities, their duration, precedence relationship of each activity and the resources required for each activity. 
Table 1: illustration problem for critic method

\begin{tabular}{|c|c|c|c|c|c|c|c|c|}
\hline \multirow{2}{*}{ Activity } & \multirow{2}{*}{$\begin{array}{c}\text { Duration } \\
\text { (days) }\end{array}$} & \multirow{2}{*}{ Predecessors } & \multicolumn{6}{|c|}{ Resource Requirements per day } \\
\hline & & & $\mathbf{R}_{1}$ & $\mathbf{R}_{2}$ & $\mathbf{R}_{3}$ & $\mathbf{R}_{4}$ & $\mathbf{R}_{5}$ & R6 \\
\hline A & 6 & - & 5 & 2 & 2 & 2 & 7 & 4 \\
\hline $\mathrm{B}$ & 3 & - & 3 & 5 & 2 & 3 & 9 & 6 \\
\hline $\mathrm{C}$ & 4 & $\mathbf{A}$ & 2 & 4 & 4 & 2 & 3 & 1 \\
\hline $\mathrm{D}$ & 6 & - & 5 & 4 & 3 & 5 & 5 & 4 \\
\hline $\mathrm{E}$ & 7 & $\mathbf{A}, \mathbf{B}$ & 3 & 5 & 2 & 3 & 8 & 0 \\
\hline $\mathrm{F}$ & 5 & $\mathrm{C}$ & 4 & 1 & 4 & 9 & 2 & 5 \\
\hline $\mathrm{G}$ & 2 & D & 4 & 1 & 4 & 3 & 9 & 8 \\
\hline $\mathrm{H}$ & 2 & $\mathbf{A}, \mathbf{B}$ & 5 & 5 & 4 & 0 & 9 & 1 \\
\hline $\mathrm{I}$ & 2 & $\mathbf{G , H}$ & 3 & 2 & 4 & 3 & 4 & 2 \\
\hline $\mathrm{J}$ & 6 & $\mathbf{F}$ & 1 & 5 & 4 & 6 & 7 & 3 \\
\hline $\mathrm{K}$ & 1 & $\mathbf{C , E}$ & 3 & 3 & 2 & 4 & 5 & 1 \\
\hline $\mathrm{L}$ & 2 & $\mathbf{E , G , H}$ & 3 & 2 & 2 & 8 & 3 & 4 \\
\hline $\mathrm{M}$ & 4 & $\mathbf{I}, \mathbf{K}$ & 2 & 2 & 2 & 2 & 4 & 8 \\
\hline $\mathrm{N}$ & 2 & $\mathbf{F}, \mathbf{L}$ & 1 & 4 & 4 & 3 & 4 & 1 \\
\hline $\mathrm{O}$ & 3 & $\mathbf{L}$ & 5 & 5 & 4 & 6 & 2 & 3 \\
\hline $\mathrm{P}$ & 5 & $\mathbf{J}, \mathbf{M}, \mathbf{N}$ & 3 & 2 & 3 & 4 & 7 & 8 \\
\hline $\mathrm{Q}$ & 8 & $\mathbf{O}$ & 4 & 5 & 4 & 2 & 3 & 4 \\
\hline $\mathrm{R}$ & 2 & $\mathrm{D}, \mathrm{O}$ & 5 & 3 & 3 & 3 & 7 & 8 \\
\hline $\mathrm{S}$ & 6 & $\mathbf{P}, \mathbf{R}$ & 2 & 4 & 6 & 2 & 3 & 4 \\
\hline $\mathrm{T}$ & 2 & $\mathbf{Q}$ & 1 & 6 & 2 & 7 & 5 & 2 \\
\hline \multicolumn{3}{|c|}{ Daily Resource Limit } & 7 & 10 & 10 & 16 & 18 & 13 \\
\hline
\end{tabular}

\subsection{Solution Procedure for Critic Method}

Step1: Developing the pair wise comparison matrix of the attributes using satty scale.

Step2: The decision matrix $\mathrm{X}$ is formed. It shows the performance of different alternatives with respect to various criteria Step3:Decision matrix is normalized using the following equation:

Step4:While determining the criteria weights, both standard deviation of the criterion and its correlation between other criteria are included. In this regard, the weight of the jth criterion (wj) is obtained as

Step5:where $\mathrm{Cj}$ is the quantity of information contained in jth criterion determined as

Step6: finding the weights and rank the weights according to the order

\subsection{Objective Function}

\section{Indices:}

$\mathrm{i}=$ Resources

$\mathrm{j}=$ Activities

$\mathrm{N}=$ no of activities

$\mathrm{W}_{\mathrm{j}}=$ objective weights of $\mathrm{jth}$ values

$\sum \boldsymbol{r}_{\boldsymbol{i j}}=$ sum of normalized resource matric

$\sigma_{j}=$ standard deviation for all the resources 
$C_{i}=$ Critic value for $\mathrm{i}^{\text {th }}$ values

$C_{j}=$ Critic value for all the $\mathrm{j}^{\text {th }}$ values

$\mathrm{W}_{\mathrm{J}}=$ weighted of activities

Estimating the criteria weights

$$
W_{j}=\frac{C_{j}}{\sum_{i=1}^{m} C_{i}}
$$

Estimating the weighted sum of the activities and ranking the activities as per their weighted sum

$$
W s=\sum_{j=1}^{k} w j\left(\frac{i j-\operatorname{minj}}{\operatorname{maxj}-\operatorname{minj}}\right)
$$

\begin{tabular}{|c|c|c|c|c|c|c|c|c|c|}
\hline Rank & Activity & Predecessor & $\begin{array}{c}\text { Duration } \\
\text { (days) }\end{array}$ & $\mathbf{R}_{1}$ & $\mathbf{R}_{\mathbf{2}}$ & $\mathbf{R}_{\mathbf{3}}$ & $\mathbf{R}_{\mathbf{4}}$ & $\mathbf{R}_{5}$ & $\mathbf{R}_{\mathbf{6}}$ \\
\hline 1 & $\mathrm{R}$ & $\mathrm{D}, \mathrm{O}$ & 2 & 5 & 3 & 3 & 3 & 7 & 8 \\
\hline 2 & $\mathrm{G}$ & $\mathrm{D}$ & 2 & 4 & 1 & 4 & 3 & 9 & 8 \\
\hline 3 & B & - & 3 & 3 & 5 & 2 & 3 & 9 & 6 \\
\hline 4 & $\mathrm{H}$ & $\mathrm{A}, \mathrm{B}$ & 2 & 5 & 5 & 4 & 0 & 9 & 1 \\
\hline 5 & $\mathrm{P}$ & $\mathrm{J}, \mathrm{M}, \mathrm{N}$ & 5 & 3 & 2 & 3 & 4 & 7 & 8 \\
\hline 6 & $\mathrm{D}$ & - & 6 & 5 & 4 & 3 & 5 & 5 & 4 \\
\hline 7 & $\mathrm{O}$ & $\mathrm{L}$ & 3 & 5 & 5 & 4 & 6 & 2 & 3 \\
\hline 8 & $\mathrm{~J}$ & $\mathrm{~F}$ & 6 & 1 & 5 & 4 & 6 & 7 & 3 \\
\hline 9 & Q & $\mathrm{O}$ & 8 & 4 & 5 & 4 & 2 & 3 & 4 \\
\hline 10 & $\mathrm{~F}$ & $\mathrm{C}$ & 5 & 4 & 1 & 4 & 9 & 2 & 5 \\
\hline 11 & $\mathrm{~S}$ & $\mathrm{P}, \mathrm{R}$ & 6 & 2 & 4 & 6 & 2 & 3 & 4 \\
\hline 12 & A & - & 6 & 5 & 2 & 2 & 2 & 7 & 4 \\
\hline 13 & $E$ & $\mathrm{~A}, \mathrm{~B}$ & 7 & 3 & 5 & 2 & 3 & 8 & 0 \\
\hline 14 & $\mathrm{~T}$ & $\mathrm{Q}$ & 2 & 1 & 6 & 2 & 7 & 5 & 2 \\
\hline 15 & $\mathrm{M}$ & $\mathrm{I}, \mathrm{K}$ & 4 & 2 & 2 & 2 & 2 & 4 & 8 \\
\hline 16 & $\mathrm{~L}$ & $\mathrm{E}, \mathrm{G}, \mathrm{H}$ & 2 & 3 & 2 & 2 & 8 & 3 & 4 \\
\hline 17 & I & $\mathrm{G}, \mathrm{H}$ & 2 & 3 & 2 & 4 & 3 & 4 & 2 \\
\hline 18 & $\mathrm{~K}$ & $\mathrm{C}, \mathrm{E}$ & 1 & 3 & 3 & 2 & 4 & 5 & 1 \\
\hline 19 & $\mathrm{C}$ & $\mathrm{A}$ & 4 & 2 & 4 & 4 & 2 & 3 & 1 \\
\hline 20 & $\mathrm{~N}$ & $\mathrm{~F}, \mathrm{~L}$ & 2 & 1 & 4 & 4 & 3 & 4 & 1 \\
\hline \multicolumn{4}{|c|}{ Daily Resource Limit } & 7 & 10 & 10 & 16 & 18 & 13 \\
\hline
\end{tabular}

Table 2: Arranging the activities as per their rank in the ascending order

Table 2 gives the information about arranging the activities as per their rank in the ascending order. From here we proceed to scheduling of the project taking into consideration of rank of the activities, precedence relationship and the resources required completing the activities. By considering all these factors here we schedule the project and the final project schedule, the critical path and the project duration is obtained from Gantt chart 


\subsection{Gantt Chart for Critic Method}

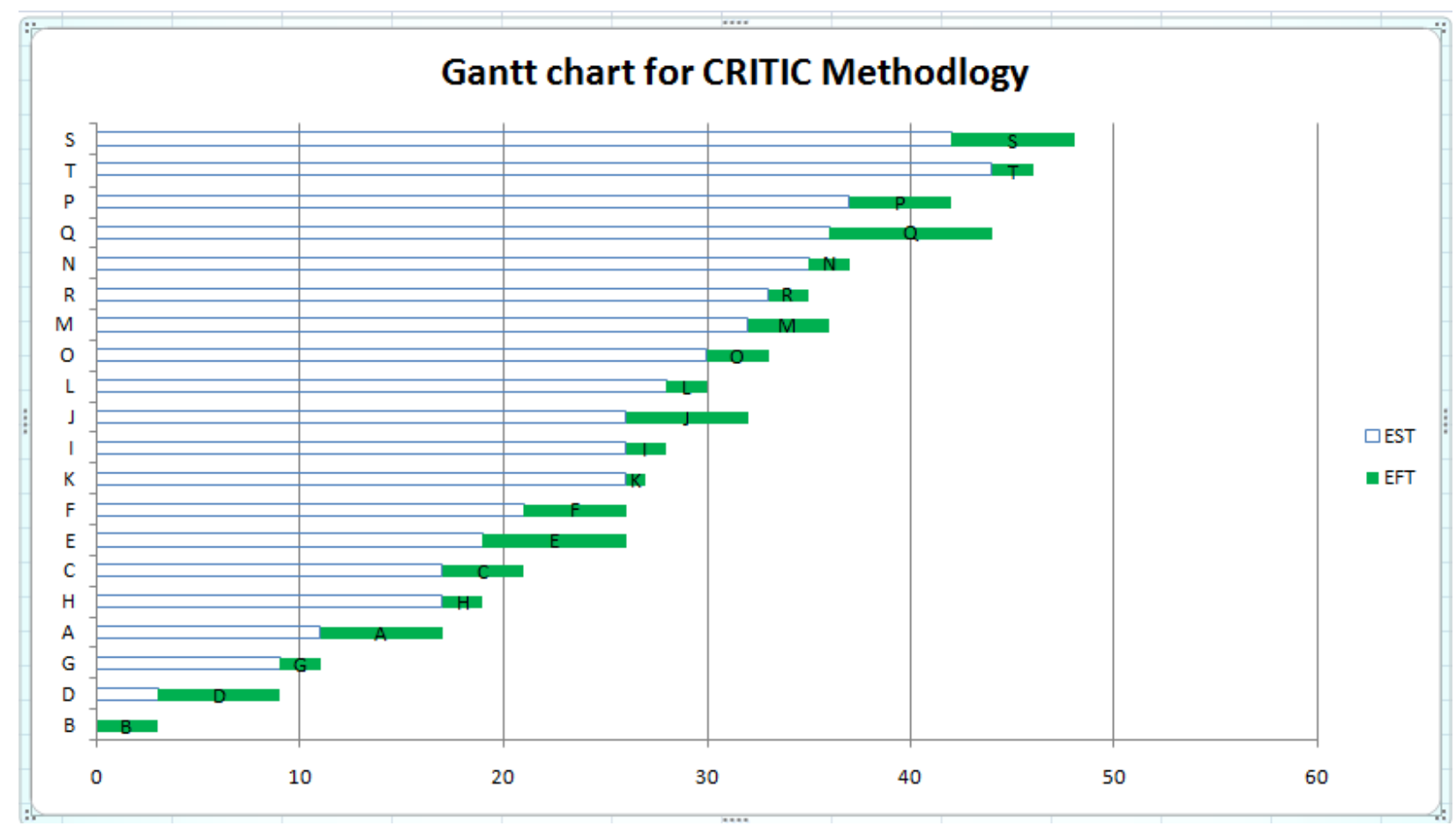

\section{CONCLUSIONS}

Considering the development during the past years, metaheuristic approaches have recently attracted more intention than other methods.CRITIC method finds objective criteria weights by eliminating decision makers' effect on the decision making process. At the same time CRITIC method does not separate the criteria as beneficial and non-beneficial and it tries to reveal the intensity of the contrast in the structure of the decision making problem The method may be performed as the corresponding This paper provides the optimum project scheduling and the project duration are obtained from the Gantt chart.

\section{REFERENCES}

1. K. K.Yang, L. C. Tay and C. C. Sum. A comparison of stochastic scheduling rules for maximizing project net present value. European Journal of Operational Research, 85 (1995), pp 327-339.

2. Chen, W. N., Zhang, J., Liu, O., \& Liu, H. L. (2010, July). A Monte-Carlo ant colony system for scheduling multi-mode projects with uncertainties to optimize cash flows. In IEEE Congress on Evolutionary Computation (pp. 1-8). IEEE

3. Choi, B. C., \& Park, M. J. (2015). A continuous time-cost tradeoff problem with multiple milestones and completely ordered jobs. European Journal of Operational Research, 244(3), 748-752

4. De Reyck, B., \&Herroelen, W. (1999). The multi-mode resource-constrained project scheduling problem with generalized precedence relations. European Journal of Operational Research, 119(2), 538556

5. Huang, W., \& Ding, L. (2011). Project-scheduling problem with random time-dependent activity duration times. IEEE Transactions on Engineering Management, 58(2), 377-387.

6. Li, H., \&Womer, N. K. (2015). Solving stochastic resource-constrained project scheduling problems by closed-loop approximate dynamic programming. European Journal of Operational Research, 246(1), 20-33 
7. Yılmaz, B. \&Harmancioğlu, N. B. (2010). Multi-criteria decision making for water resource management: a case study of the Gediz River Basin, Turkey. Water SA, 36(5), 563-576.

8. Madic, M. \&Radovanović, M. (2015). Ranking of some most commonly used nontraditional machining processes using ROV and CRITIC methods. U.P.B. Sci. Bull., Series D, 77(2), 193-204.

9. Milić, M.R. \&Goran, Z.Z. (2012). Objektivnipristupodređivanjutežınakriterijuma (An objective approach to determining criteria weights). Vojnotehnıčkıglasnık/mılıtary technıcal courıer, 60(1), 39-56.

10. Guo, C., Wang, Y. \& Jiang, W. (2013). An empirical study of evaluation index system and measure method on city's soft power: 17 cities in Shandong province. Cross-Cultural Communication, 9(6), 27-31

11. Liu, D. \& Zhao, X. (2013). Method and application for dynamic comprehensive evaluation with subjective and objective information. PLOS ONE, 8(12), 1-5.

12. Kazan, H. \&Ozdemir, O. (2014). Financial performance assessment of large scale conglomerates via TOPSIS and CRITIC methods. International Journal of Management and Sustainability, 3(4), 203-224.

13. Alemiardakani, M. (2014). Enhancing Impact Characterization and Multi-Criteria Design Optimization of Glass Fiber Reinforced Polypropylene Laminates (Doctor of Philosophy), The University of British Columbia, Canada.

14. Kim, J. \& Yu, K. (2015). Areal feature matching based on similarity using CRITIC method. Joint International Geoinformation Conference, 28-30 October, Kuala Lumpur, Malaysia, 75-78. 